\title{
Erratum to: Determinants of exclusive breastfeeding cessation: identifying an "at risk population" for special support
}

\author{
Juliana F. Lindau • Simona Mastroeni • Andrea Gaddini • \\ Domenico Di Lallo • Paolo Fiori Nastro • \\ Martina Patanè • Paolo Girardi • Cristina Fortes
}

Published online: 3 December 2014

(C) Springer-Verlag Berlin Heidelberg 2014

\section{Erratum to: Eur J Pediatr}

DOI 10.1007/s00431-014-2428-x

The original version of this article unfortunately contains an error in the name of one of the authors that was overlooked by the authors in the proof stage. The name Paolo Fiori Nastro should be presented as P. Fiori Nastro instead of P. F. Nastro. The correct presentation of author name is presented in the affiliation section

The online version of the original article can be found at http://dx.doi.org/ 10.1007/s00431-014-2428-x.

J. F. Lindau $\cdot$ P. Girardi

NESMOS Department (Neurosciences, Mental Health and Sensory Functions), 2nd Medical School, Sant'Andrea Hospital, Sapienza

University, Rome, Italy

J. F. Lindau

e-mail: juliana_lindau@hotmail.com

P. Girardi

e-mail: paolo.girardi@uniromal.it

S. Mastroeni · C. Fortes $(\square)$

Clinical Epidemiology Unit, Istituto Dermopatico dell'Immacolata,

IDI-IRCCS, Via dei Monti di Creta, 104, 00167 Rome, Italy

e-mail: c.fortes@idi.it

S. Mastroeni

e-mail: s.mastroeni@idi.it
A. Gaddini $\cdot$ D. Di Lallo

Public Health Agency, Rome, Lazio Regium, Italy

A. Gaddini

e-mail: andrea.gaddini@gmail.com

D. Di Lallo

e-mail: matinf@asplazio.it

P. Fiori Nastro $\cdot$ M. Patanè

Department of Neurology and Psychiatry, 1st University School of Medicine, Sapienza University, Rome, Italy

P. Fiori Nastro

e-mail: paolo.fiorinastro@uniroma1.it

M. Patanè

e-mail: martina.patane@gmail.com 